Check for updates

Cite this: RSC Adv., 2017, 7, 31352

Received 16th March 2017

Accepted 9th June 2017

DOI: 10.1039/c7ra03111d

rsc.li/rsc-advances

\section{Facile synthesis of potassium copper ferrocyanide composite particles for selective cesium removal from wastewater in the batch and continuous processes}

\author{
Youli Zong, ${ }^{\mathrm{b}}$ Yongde Zhang, (D) *ab Xiaoyan Lin, ${ }^{\mathrm{ab}}$ Dong Ye, ${ }^{\mathrm{b}}$ Dan Qiao \\ and Shuangneng Zeng ${ }^{\mathrm{b}}$
}

A composite potassium copper ferrocyanide particle adsorbent (CMC-KCUFC) was fabricated in this study, based on the use of a carboxymethyl cellulose sodium (CMC) biopolymer cross-linked with $\mathrm{Cu}^{2+}$ via a syringe pump device, serving as an efficient biosorbent for cesium (Cs) ion removal and adsorption from wastewater, and was verified by SEM, EDX, FT-IR, TGA and XRD. Influencing factors in the adsorption of cesium were systematically investigated, including the $\mathrm{pH}$ of the solution, contact time, initial concentration, temperature and competing ions. The results demonstrated that use of the CMCKCuFC adsorbent was feasible under a wide range of $\mathrm{pH}$ values (5-10). The cesium adsorption process was described by the Freundlich isotherm model. Meanwhile, the adsorption equilibrium time was reached within 600 min and the kinetic study showed it to be well fitted by the pseudo-second-order kinetic model. Moreover, all materials involved in the CMC-KCUFC adsorbent were biosafe and biodegradable. CMC-KCUFC is expected to be a potential adsorbent for continuous removal of cesium from wastewater.

\section{Introduction}

In the recent years, there have been growing concerns regarding the contamination caused by radioactive waste. The treatment of radionuclide wastewater is in urgent need, especially after the Fukushima Daiichi nuclear disaster in 2011. Of all the radionuclides, 137 -cesium $\left({ }^{137} \mathrm{Cs}\right)$ has attracted great attention due to its long half-life ( $T_{1 / 2}=30.17$ years), high energy gamma ray emission and high solubility in water, ${ }^{1-3}$ which can cause adverse effects on the environment and human health. A weak Lewis acid, the $\mathrm{Cs}^{+}$ion, exhibits a low tendency to form complexes with ligands. Meanwhile, because of its chemical similarity to potassium, ${ }^{137} \mathrm{Cs}$ can be easily incorporated into terrestrial and living organisms where it is deposited in the soft tissues, leading to cancer., ${ }^{4,5}$ Hence, development of an efficient and economical removal method is principal for the removal of cesium from wastewater in view of the environmental risks.

To date, various methods have been proposed for removal of radiocesium from wastewater, the most main used are solvent extraction, ${ }^{6,7}$ chemical precipitation ${ }^{8}$ and adsorption method. ${ }^{9}$ Among these methods, adsorption has been proved to be an

${ }^{a}$ Department of Materials Science and Engineering, Southwest University of Science and Technology, Mianyang, Sichuan 621010, China. E-mail: zhangyongde1969@ 126.com

${ }^{b}$ Engineering Research Center of Biomass Materials, Ministry of Education, Mianyang, Sichuan 621010, China excellent way to treat wastewater, offering significant advantages, like the low-cost, availability, profitability, easy operation, and efficiency. ${ }^{10}$ A variety of ${ }^{137} \mathrm{Cs}$ adsorbent materials, including clay minerals, metal oxides, zirconium phosphate and silicotitanates are all previously reported for removal of cesium, ${ }^{11-15}$ whereas the limitation of the low $\mathrm{Cs}^{+}$selectivity or too expensive for large-scale application in environmental cleanup. Accordingly, new adsorption materials are necessary to be researched.

Transition metal ( $\mathrm{Cu}, \mathrm{Fe}, \mathrm{Ni}, \mathrm{Zn}$ and $\mathrm{Co}$ ) hexacyanoferrates (MCFs) are considered to be one of the inorganic adsorbents for selective recovery of cesium from wastewater. Among them, potassium copper hexacyanoferrate (KCuFC) is often chosen as the agent in practical application. Due to it is available in powdery and granular form compared to other metal hexacyanoferrates. ${ }^{16}$ Moreover, its radiation stability, high selectivity, low cost and excellent ion exchange performance in a broad range of $\mathrm{pH}$ make its feasible for large-scale application. ${ }^{17,18}$ Nevertheless, direct use of KCuFC as adsorbent has been hampered by its fine powder morphology, and it is unsuitable for continuous column stuffing and difficult to remove from solutions. ${ }^{19,20}$ To solve this problem, the immobilization of KCuFC particles into polymers is a key technology to apply these particles for the large-scale applications. An organic polymer, biopolymer carboxymethyl cellulose (CMC) is a desirable candidate for immobilizing agent, due to its unique 
characteristics such as solubility, non-toxicity and biocompatibility. Furthermore, in the presence of $\mathrm{Cu}^{2+}, \mathrm{Fe}^{3+}, \mathrm{La}^{3+}$ and $\mathrm{Al}^{3+}$ etc. ${ }^{21} \mathrm{CMC}$ can form stable ionotropic gels. Among them, $\mathrm{Cu}^{2+}$ can be used as an ecofriendly and nontoxic crosslinking agent for CMC. Additionally, it is one of the raw materials for the synthesis of the KCuFC and does not produce secondary pollution after adsorption. The chemical structure of CMC is shown in Fig. 1.

This work synthesized a novel adsorbent of CMC-KCuFC particles by using copper chloride cross-linked carboxymethyl cellulose sodium (CMC) biopolymer as the immobilized matrix, and built particles within the polymer through a syringe pump for recovering cesium from wastewater. The composite particle was prepared using only eco-friendly materials at room temperature. FT-IR, XRD and SEM were utilized to characterize the extraction mechanism of adsorbent. In addition, to evaluate the adsorption capacity of cesium from aqueous solution in detail under various experimental conditions, isotherm and kinetic models were investigated to understand the adsorption process.

\section{Materials and methods}

\subsection{Reagents}

Sodium carboxymethyl cellulose (CMC, 1000-1400 mPa s, USP grade) was purchased from Aladdin Chemistry Co. Ltd. (Shanghai, China). Copper(II) chloride dihydrate $\left(\mathrm{CuCl}_{2} \cdot 2 \mathrm{H}_{2} \mathrm{O}\right)$, potassium hexacyanoferrate(II) trihydrate $\left(\mathrm{K}_{4}\left[\mathrm{Fe}(\mathrm{CN})_{6}\right] \cdot 3 \mathrm{H}_{2} \mathrm{O}\right)$, cesium chloride ( $\mathrm{CsCl}), \mathrm{NaOH}$ and $\mathrm{HCl}$ were purchased from Chengdu Kelong Chemicals Company. Stock solution of $20 \mathrm{mg}$ $\mathrm{L}^{-1}$ cesium ion aqueous solution was prepared by dissolving $0.0253 \mathrm{~g} \mathrm{CsCl}$ in $1000 \mathrm{~mL}$ deionized water. Besides, all reagents in experiment were of analytical reagent grade and used without further purification.

\subsection{Preparation of $\mathrm{CMC}-\mathrm{KCuFC}$ particles and $\mathrm{CMC}-\mathrm{Cu}$ particles}

$2 \mathrm{~g}$ of CMC was dissolved in $100 \mathrm{~mL}$ of $2.5 \%(\mathrm{w} / \mathrm{v}) \mathrm{K}_{4}\left[\mathrm{Fe}(\mathrm{CN})_{6}\right]$ solution under constant agitating for $4 \mathrm{~h}$ at room temperature, then ultrasonicated for several minutes to obtain a homogeneous solution. The mix solution was added drop-wise with continuous stirring to $100 \mathrm{~mL}$ of $2 \%(\mathrm{w} / \mathrm{v}) \mathrm{CuCl}_{2}$ solution, using a syringe pump (Model: LSP02-1B) at the speed of $1 \mathrm{~mL} \mathrm{~min}^{-1}$, and then the coagulated particles (CMC-KCuFC) were stirred

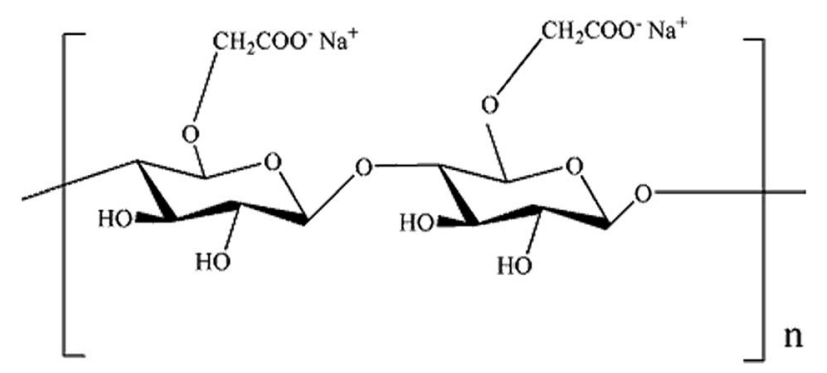

Fig. 1 Chemical structure of CMC. continuously for $12 \mathrm{~h}$. After that, the CMC-KCuFC particles were collected by rinsing several times with deionized water until removing the residual $\mathrm{Cu}$ (II) ions. Finally, the $\mathrm{CMC}-\mathrm{KCuFC}$ particles were dried in oven at $50{ }^{\circ} \mathrm{C}$ for use in further studies. The preparation process schematic diagram was displayed in Fig. 2.

The following $\mathrm{CMC}-\mathrm{Cu}$ particles were prepared by a similar method to that of preparation of $\mathrm{CMC}-\mathrm{KCuFC}$ particles. Specifically, $2 \mathrm{~g}$ of CMC was dissolved in $100 \mathrm{~mL}$ of distilled water with vigorous magnetic stirring for $4 \mathrm{~h}$ at room temperature, and then ultrasonicated for several minutes to obtain a homogeneous solution. The CMC solution was dropped into $100 \mathrm{~mL} \%(\mathrm{w} / \mathrm{v}) \mathrm{CuCl}_{2}$ solution, using a syringe pump (Model: LSP02-1B) at the speed of $1 \mathrm{~mL} \mathrm{~min}^{-1}$, and then the coagulated particles $(\mathrm{CMC}-\mathrm{Cu})$ were stirred continuously for $12 \mathrm{~h}$. After that, the $\mathrm{CMC}-\mathrm{Cu}$ particles were washed with deionized water to residual $\mathrm{Cu}(\mathrm{II})$ ions. Finally, the $\mathrm{CMC}-\mathrm{Cu}$ particles were dried $50{ }^{\circ} \mathrm{C}$ in an oven.

\subsection{Batch adsorption experiment for cesium}

Inactive cesium was used to research the adsorption behaviors. In brief, all adsorption experiments were carried out on thermostatic shaker (HZQ-2) with a constant speed of $150 \mathrm{rpm}$ by using batch technique. Initial $\mathrm{pH}$, contact time, initial concentration and temperatures and competing ions on adsorption of cesium were evaluated in $50 \mathrm{~mL}$ of test solutions with $0.01 \mathrm{~g}$ (dry weight) CMC-KCuFC particles. Besides, $0.05 \mathrm{~mol} \mathrm{~L}^{-1} \mathrm{HCl}$ and $0.05 \mathrm{~mol} \mathrm{~L}^{-1} \mathrm{NaOH}$ were used to adjust the $\mathrm{pH}$ value of the solution. The concentrations of $\mathrm{Cs}^{+}$ remaining in the solution were quantified with a Hitachi Z-2000 Zeeman atomic absorption spectrophotometer with air-acetylene flame (AAS) before and after adsorption. Each sample was designed in triplicate, and the average values were used to evaluate the adsorbent capabilities. The adsorption capacity at equilibrium $\left(q_{\mathrm{e}}\right)$ and elimination efficiency $(E \%)$ of the cesium ions can be evaluated using eqn (1) and (2), respectively. ${ }^{19,22}$

$$
q_{\mathrm{e}}=\left(C_{0}-C_{\mathrm{e}}\right) V / m
$$

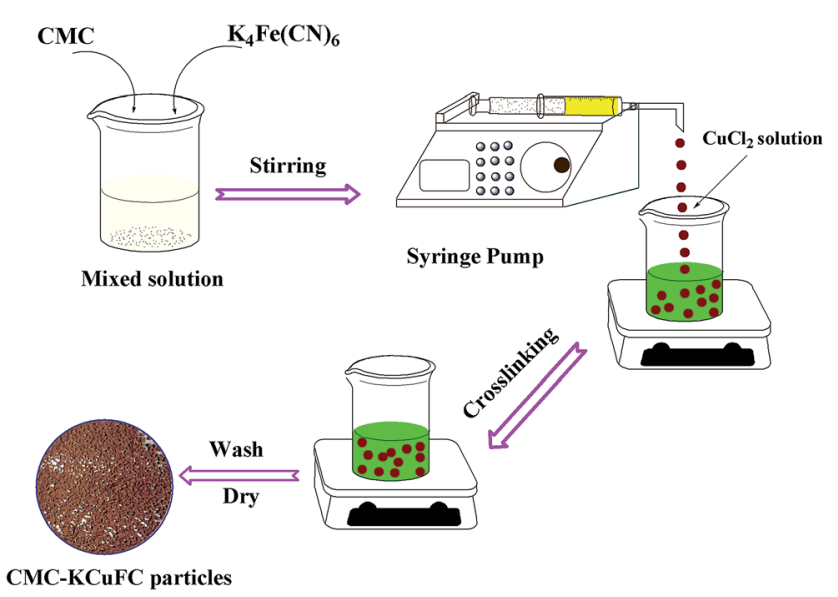

Fig. 2 Schematic presentation of the preparation process of CMCKCUFC. 


$$
E(\%)=\left(C_{0}-C_{\mathrm{e}}\right) / C_{0} \times 100
$$

where $C_{0}\left(\mathrm{mg} \mathrm{L}^{-1}\right)$ and $C_{\mathrm{e}}\left(\mathrm{mg} \mathrm{L}^{-1}\right)$ are the initial cesium concentration and cesium concentration at equilibrium in the aqueous solution, respectively. $V(\mathrm{~mL})$ is the volume of cesium solution and $m(\mathrm{~g})$ is the dry weight of the adsorbent.

\subsection{Fixed bed column study}

In order to study the dynamic behavior of the continuous adsorption of $\mathrm{Cs}^{+}$ions from aqueous solution by CMC-KCuFC particles, fixed bed column adsorption experiments were investigated. The column experiments were carried out in a glass column with an inner diameter $(\mathrm{ID}=1.5 \mathrm{~cm})$ and length ( $L=35 \mathrm{~cm}$ ). Column was filled with adsorbent between two supporting layers of glass wool. CMC-KCuFC particles were added from the top of the column. The cesium ions solution is pumped upwards the adsorber from a liquid holding tank, and the inlet flow rate was controlled by using a peristaltic pump. Effluent samples are collected in regular time intervals and stored for analysis, and the influent and effluent cesium concentrations were measured by the AAS. The schematic diagram of the fixed-bed adsorption system was shown in Fig. 3.

\subsection{Characterization of the CMC-KCuFC particles}

The surface morphology of the adsorbent was characterized by TM3000 scanning electron microscope (SEM). The specific surface area and pore volume of the adsorbent was determined by surface area analyzer (BET, JW-BK112). X-ray spectroscopy (EDX, Ultra 55, Carl Zeiss, Germany) was employed to detect the element composition of the adsorbent surface coated with gold. The surface functional groups of the adsorbent was demonstrated by the Fourier transform infrared spectra (FT-IR, Nicolet-5700, PerkinElmer Instruments Corporation) and adopting the $\mathrm{KBr}$ pellet technique, over the spectral range of $4000-400 \mathrm{~cm}^{-1}$. XRD patterns of adsorbent crystalline structure were analyzed by X'Pert PRO (PANalytical B.V., $40 \mathrm{kV}, 40 \mathrm{~mA}$ ) equipped with a $\mathrm{Cu} \mathrm{K} \alpha$ source at $2 \theta$ range from $10^{\circ}$ to $80^{\circ}$. The thermal stabilities of adsorbent were measured using thermogravimetric analysis (TGA, Q600, USA), the samples were

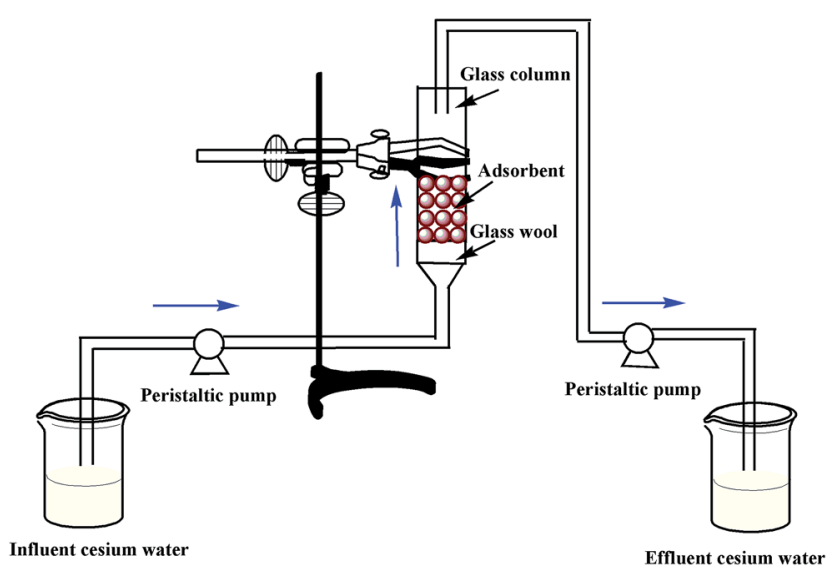

Fig. 3 Schematic diagram of the fixed-bed adsorption experiment. gradually heated at a rate of $20{ }^{\circ} \mathrm{C} \min ^{-1}$ from 20 to $800{ }^{\circ} \mathrm{C}$

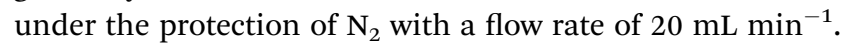

\section{Results and discussion}

\subsection{Batch experiments}

3.1.1. Effect of CMC-KCuFC particles size. In order to investigate the effect of CMC-KCuFC particles size on adsorption of cesium, CMC-KCuFC particles were controlled by different size of syringe needle, the results are shown in Fig. 4, it can be seen that the adsorption capacity decreased slightly with the increase in particles size from 1.5 to $2.0 \mathrm{~mm}$, an effect that might be attributed to the amount of active sites on the adsorbent surface during the adsorption operation process.

3.1.2. Effect of $\mathbf{p H}$. The $\mathrm{pH}$ of solution played a vital role to affect the chemical reactions and adsorption behavior, especially for ion-exchange process. ${ }^{23,24}$ To choose optimal $\mathrm{pH}$ for the removal of cesium, the effect of $\mathrm{pH}$ on CMC-KCuFC particle was studied in the range of 2-10. The results were shown in Fig. 5. It can be seen that the adsorption capacity increased apparently with increasing $\mathrm{pH}$ from 2 to 5 , while the adsorption capacity remained steady up when the $\mathrm{pH}$ was in the range of 5 to 10 . This occurred because that at low $\mathrm{pH}$, ion exchange sites were mainly protonated, making them less available for cation. ${ }^{25}$ However, when the $\mathrm{pH}$ increased, the sites became available for cation in ion-exchange processes, leading to higher adsorption. Even though, the adsorption capacity of cesium ions was feasible across a wide range of $\mathrm{pH}$ values, if the $\mathrm{pH}$ was at least 5 or above. ${ }^{26}$

3.1.3. Effect of contact time and kinetics of cesium adsorption study. Effect of contact time on the adsorption capacity and elimination efficiency of $\mathrm{CMC}-\mathrm{Cu}$ and $\mathrm{CMC}-$ KCuFC particles were given in Fig. 6, respectively. It was shown that over $61.67 \%$ of Cs was removed after 600 min with CMCKCuFC, while only $5.56 \%$ was removed with $\mathrm{CMC}-\mathrm{Cu}$ and $q_{\mathrm{e}}$ value was $7.85 \mathrm{mg} \mathrm{g}^{-1}$ at relatively low cesium concentration,

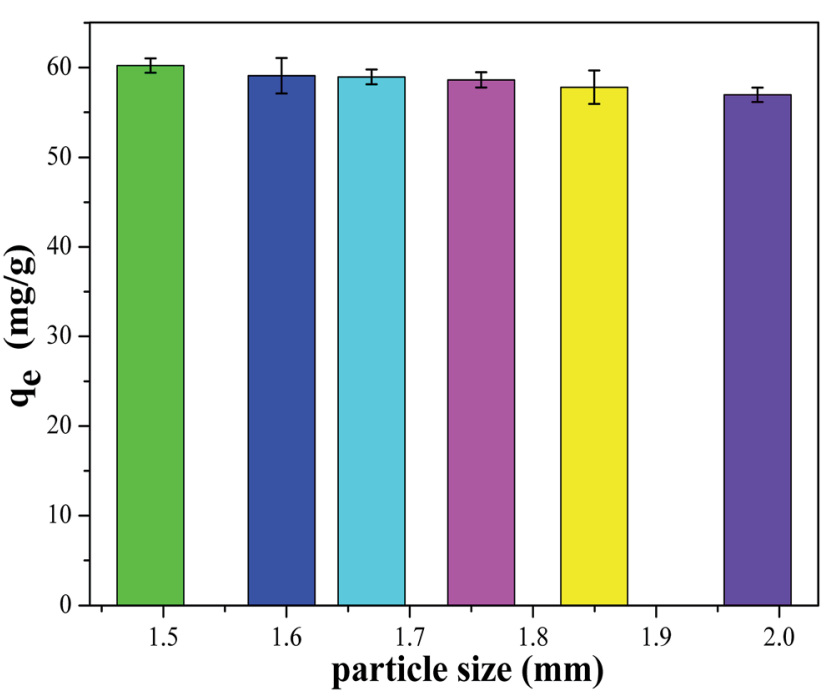

Fig. 4 Effect of particle size of CMC-KCuFC particles on cesium adsorption. 


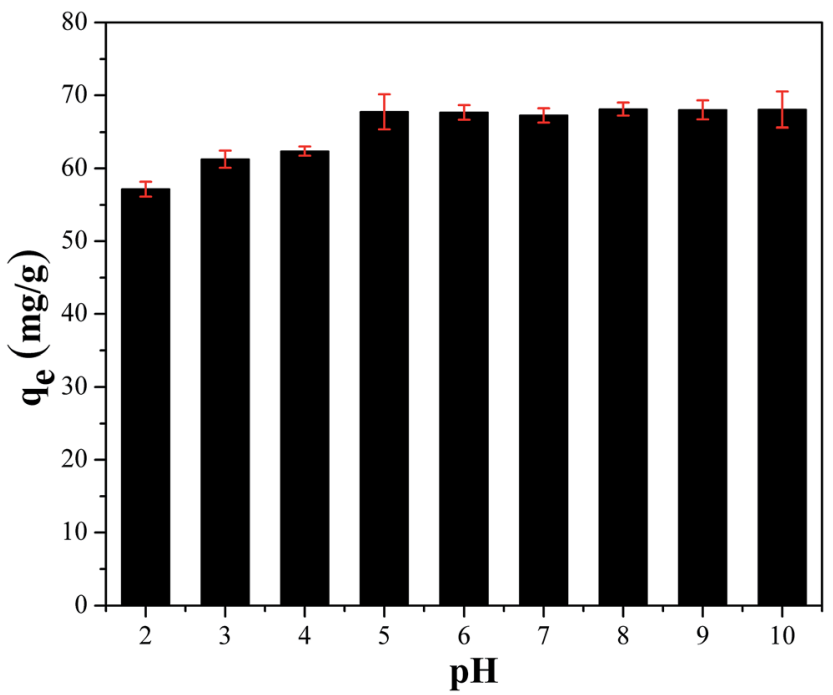

Fig. 5 Effect of $\mathrm{pH}$ on adsorption capacity on the remove of $50 \mathrm{~mL}$ $20 \mathrm{mg} \mathrm{L}^{-1} \mathrm{Cs}^{+}$for $24 \mathrm{~h}$ at $298.15 \mathrm{~K}$.

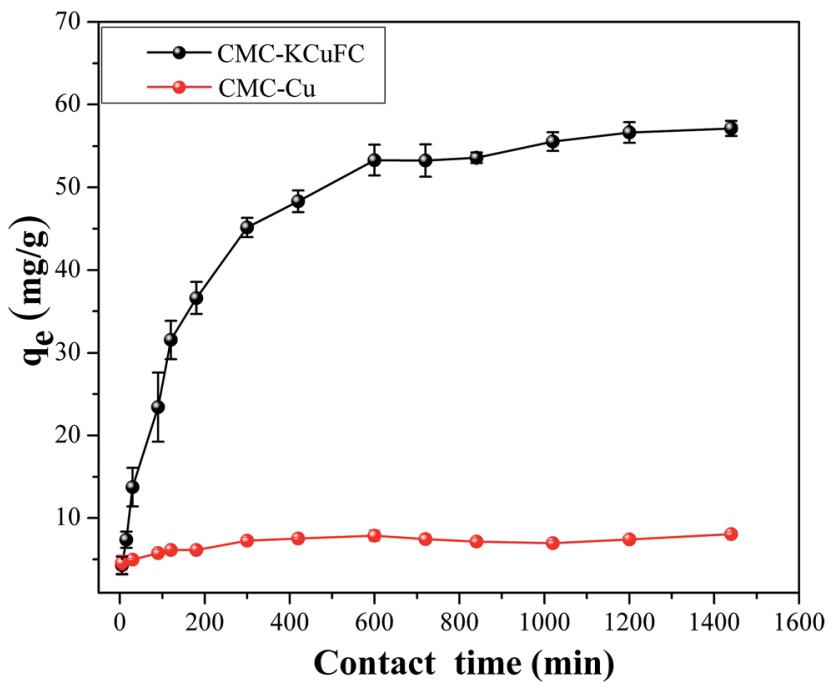

Fig. 6 Effect of contact time on the remove of $50 \mathrm{~mL} 20 \mathrm{mg} \mathrm{L}^{-1} \mathrm{Cs}^{+}$ for $24 \mathrm{~h}$ at $298.15 \mathrm{~K}$.

which was specially revealed that the adsorbance of $\mathrm{CMC}-\mathrm{Cu}$ for cesium in wastewater was insignificant. Therefore, the adsorption of CMC-KCuFC for cesium should be attributed to the existence of KCuFC crystals.

The kinetic studies were used to evaluate the mechanism of interaction between the adsorbent and the adsorbate. For this purpose, the kinetics was analyzed using pseudo-first-order and pseudo-second-order kinetic model. The equations of both linear models can be expressed as follows: $:^{27,28}$

$$
\begin{gathered}
\log \left(q_{\mathrm{e}}-q_{t}\right)=\log q_{\mathrm{e}}-k_{1} t / 2.303 \\
t / q_{t}=t / q_{\mathrm{e}}+1 / k_{2} q_{\mathrm{e}}{ }^{2}
\end{gathered}
$$

where $q_{\mathrm{e}}\left(\mathrm{mg} \mathrm{g}^{-1}\right)$ and $q_{t}\left(\mathrm{mg} \mathrm{g}^{-1}\right)$ are the adsorption capacity at equilibrium and at any time $t$, respectively. $t(\mathrm{~min})$ is the contact time. $k_{1}\left(\mathrm{~min}^{-1}\right)$ is the pseudo-first-order rate constant, while $k_{2}$ $\left(\mathrm{g}\left(\mathrm{mg}^{-1} \mathrm{~min}^{-1}\right)\right)$ is the pseudo-second-order rate constant for cesium adsorption process. $k_{1}$ and $k_{2}$ can be obtained from the plot of experimental data.

The linear fitting of pseudo-first-order and pseudo-secondorder model were shown in Fig. 7. The calculated parameters of $q_{\mathrm{e}}, k_{1}$ and $k_{2}$ were tabulated in Table 1 , respectively. Compared with the two models, the correlation coefficient $\left(R^{2}=\right.$ 0.999) of pseudo-second-order model was higher than pseudofirst-order model. Besides, the calculated equilibrium adsorption capacity $q_{\mathrm{e}}\left(60.827 \mathrm{mg} \mathrm{\textrm {g } ^ { - 1 }}\right)$ in pseudo-secondorder kinetics model was closer to the experimental data $\left(57.133 \mathrm{mg} \mathrm{g}^{-1}\right)$. It was demonstrated that the adsorption of cesium obeyed the pseudo-second-order kinetic model over the whole adsorption process, implying that the main rate limiting step was chemical adsorption involved valence forces through sharing or exchange of electrons between the adsorbent and adsorbate. ${ }^{23,28}$ The maximum adsorption capacity was $60.827 \mathrm{mg} \mathrm{g}^{-1}$.

3.1.4. Effect of initial cesium concentration and adsorption isotherm model. The effect of different initial cesium concentrations varying from 10 to $100 \mathrm{mg} \mathrm{L}^{-1}$ at different temperatures were showed in Fig. 8. It was found that all the adsorption capacity increased rapidly at the initial concentration of $10-40 \mathrm{mg} \mathrm{L}^{-1}$ and increased slowly within the concentration of $40-100 \mathrm{mg} \mathrm{L}^{-1}$ in the range of temperature from 288.15 to $328.15 \mathrm{~K}$. This may be explained that the increasing initial cesium solution concentration of cesium provided a necessary driving force to overcome all the mass transfer resistance to the $\mathrm{Cs}^{+}$between the aqueous and solid phases, and then a lower number of coordination sites were available when the adsorption capacity tended to saturate. ${ }^{29}$

Equilibrium isotherms provided information about the adsorption mechanism, surface properties and the affinity of the adsorbent. In this study, Langmuir and Freundlich models were utilized to describe the relationship between adsorbed cesium and its residual in aqueous solution at adsorption equilibrium. The equation of linear Langmuir model can be written as: ${ }^{30}$

$$
C_{\mathrm{e}} / q_{\mathrm{e}}=1 /\left(K_{\mathrm{L}} q_{\mathrm{m}}\right)+C_{\mathrm{e}} / q_{\mathrm{m}}
$$

While Freundlich isotherm explains multilayer adsorption on heterogeneous surfaces in nature. ${ }^{31}$ The linear Freundlich model can be expressed as:

$$
\ln q_{\mathrm{e}}=\ln K_{\mathrm{F}}+\frac{1}{n} \ln C_{\mathrm{e}}
$$

where $q_{\mathrm{e}}\left(\mathrm{mg} \mathrm{g}^{-1}\right)$ is the adsorption capacity of cesium on the adsorbent at equilibrium, $C_{0}\left(\mathrm{mg} \mathrm{L}^{-1}\right)$ and $C_{\mathrm{e}}\left(\mathrm{mg} \mathrm{L}^{-1}\right)$ are the initial cesium concentration and equilibrium cesium concentration, respectively. $K_{\mathrm{L}}\left(\mathrm{L} \mathrm{mg^{-1 } )}\right.$ is the calculated Langmuir constant related to the energy of adsorption and $q_{\mathrm{m}}\left(\mathrm{mg} \mathrm{g}^{-1}\right)$ is the monolayer adsorption capacity. $K_{\mathrm{F}}\left(\mathrm{mg} \mathrm{g}^{-1}\right)$ is the 

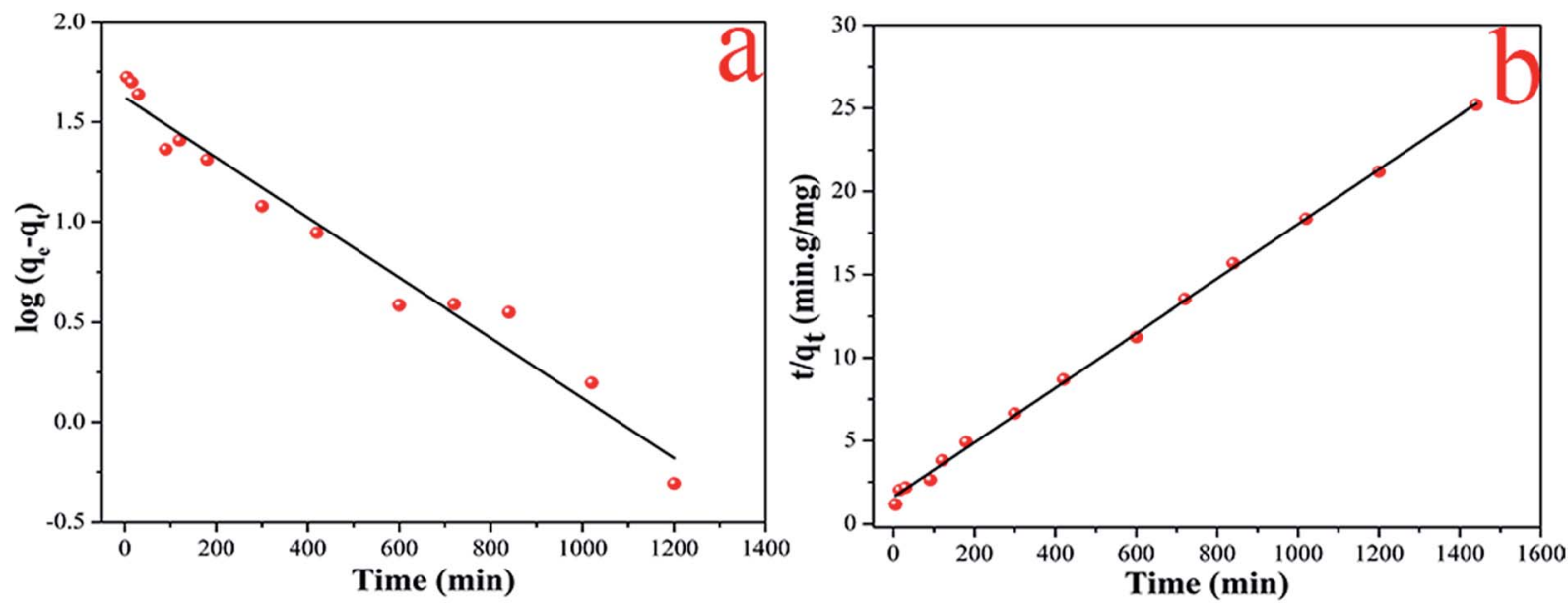

Fig. 7 The linear fitting of pseudo-first-order kinetic models (a) and pseudo-second-order kinetic models (b) of $\mathrm{Cs}^{+}$.

Table 1 Parameters of linear pseudo-first-order kinetics and pseudo-second-order kinetics

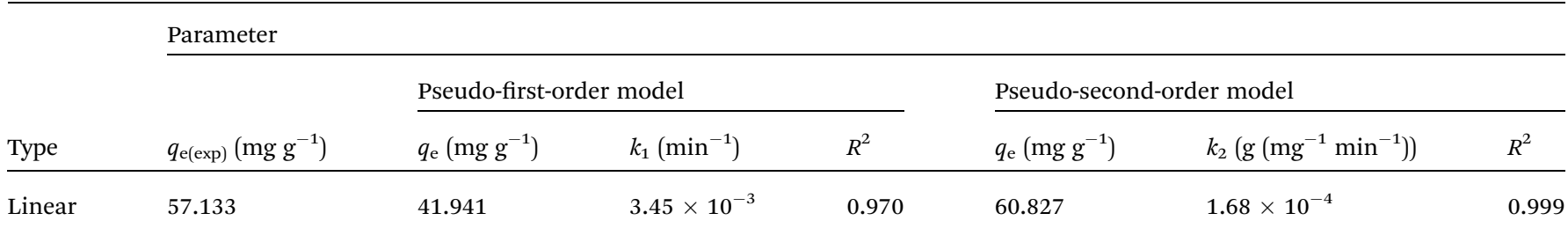

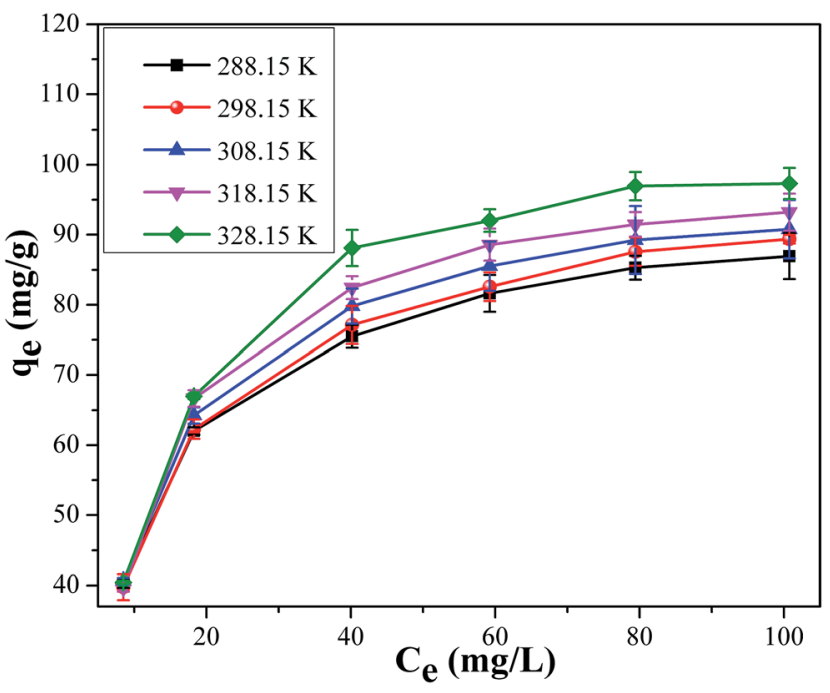

Fig. 8 Effect of initial concentration on adsorption capacity of $50 \mathrm{~mL}$ $\mathrm{Cs}^{+}$for $24 \mathrm{~h}$ at $288.15-328.15 \mathrm{~K}$

Freundlich constant indicates the multilayer adsorption capacity and $n$ is the intensity of adsorption.

The Langmuir and Freundlich values of $q_{\mathrm{m}}, K_{\mathrm{L}}, n$ and $K_{\mathrm{F}}$ can be obtained from the slope and intercept of the plots (Fig. 9), and the results were listed in Table 2 . As evidenced by the correction coefficient $R^{2}$, the Freundlich model presented more suitable than Langmuir model, indicating that the adsorption process belongs to multilayer adsorption with non-uniform distribution of adsorption heat and affinities over the heterogeneous surface. Additionally, the obtained $1 / n$ values were between 0 and 1, indicating a highly favorable interaction in the whole adsorption process.

3.1.5. Effect of temperatures and the evaluation of adsorption thermodynamics. Effect of various temperatures on the adsorption of cesium onto $\mathrm{CMC}-\mathrm{KCuFC}$ particle was investigated at different initial concentrations range from 10 to $100 \mathrm{mg} \mathrm{L}^{-1}$. As shown in Fig. 10, while increasing the temperature from 288.15 to $328.15 \mathrm{~K}$ the influence of temperature was not obvious at all the initial concentrations ranging from 10$100 \mathrm{mg} \mathrm{L}^{-1}$. Therefore, from the aspect of energy saving, the following experiments were all conducted at $298.15 \mathrm{~K}$.

In order to evaluate the thermodynamic feasibility and under the nature of the adsorption process, three basic thermodynamic parameters $\left(\Delta H^{\mathrm{o}}, \Delta S^{\mathrm{o}}\right.$ and $\left.\Delta G^{\mathrm{o}}\right)$ were calculated by the following. ${ }^{31,32}$

$$
\begin{gathered}
K_{\mathrm{d}}=q_{\mathrm{e}} / C_{\mathrm{e}} \\
\ln K_{\mathrm{d}}=\Delta S^{\mathrm{o}} / R-\Delta H^{\mathrm{o}} / R T \\
\Delta G^{\mathrm{o}}=\Delta H^{\mathrm{o}}-T \Delta S^{\mathrm{o}}
\end{gathered}
$$

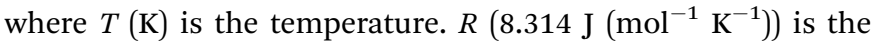
universal gas constant. $K_{\mathrm{d}}\left(\mathrm{mL} \mathrm{g}^{-1}\right)$ is the distribution coefficient. $\Delta H^{\mathrm{o}}\left(\mathrm{kJ} \mathrm{mol}^{-1}\right), \Delta S^{\mathrm{o}}\left(\mathrm{J}\left(\mathrm{mol}^{-1} \mathrm{~K}^{-1}\right)\right), \Delta G^{\mathrm{o}}\left(\mathrm{kJ} \mathrm{mol}^{-1}\right)$ are in the enthalpy change, entropy change and Gibbs free energy for the adsorption process, respectively. The values of $\Delta H^{\mathrm{o}}$ and $\Delta S^{\mathrm{o}}$ 

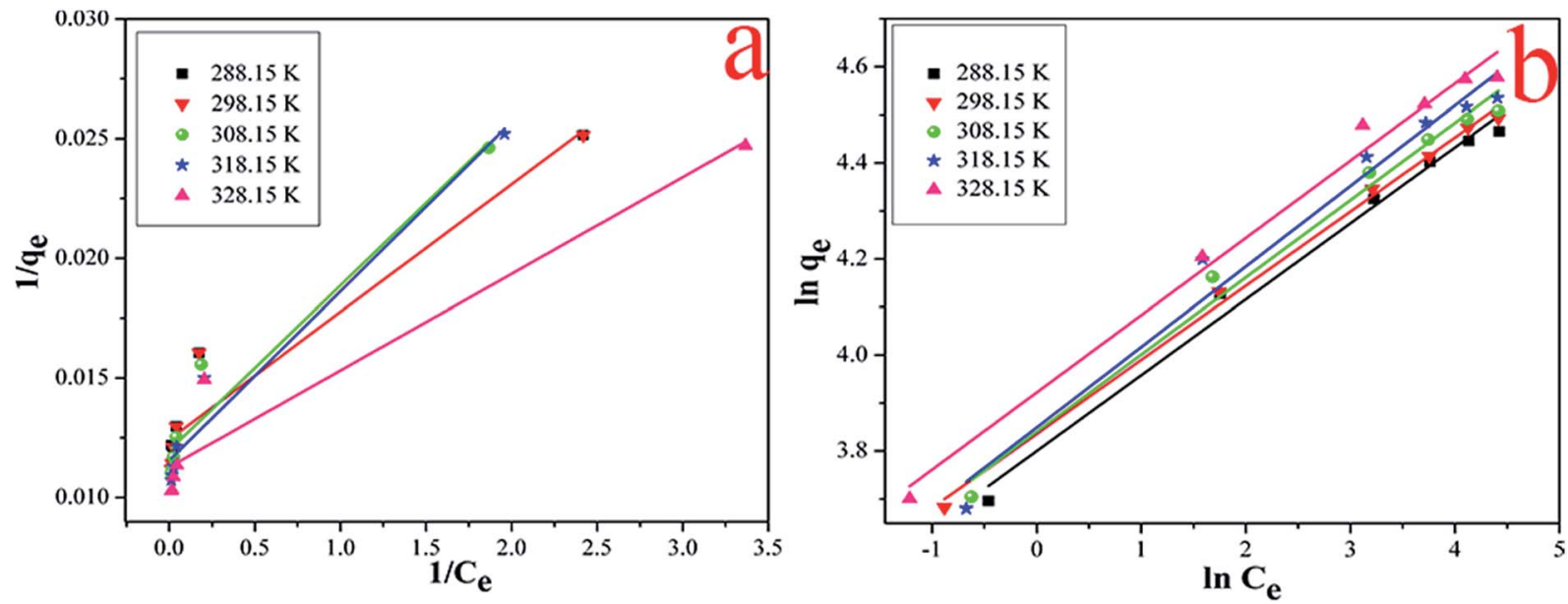

Fig. 9 The linear of Langmuir models (a) and Freundlich models (b) of $\mathrm{Cs}^{+}$.

Table 2 The linear of Langmuir and Freundlich models

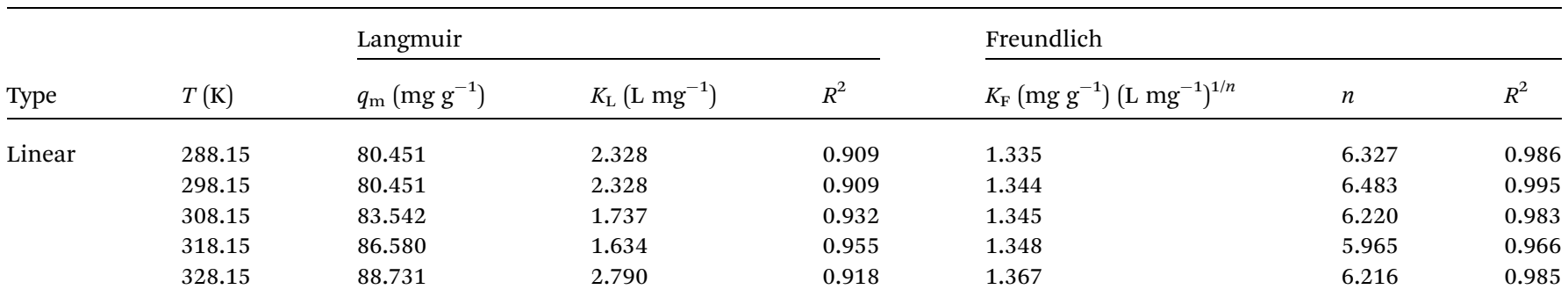

can be obtained from the slope and intercept of the Van't Hoff linear plots of $\ln K_{\mathrm{d}}$ versus $1 / T$. The results were shown in Fig. 11. Meanwhile, the values of thermodynamic parameters for the adsorption of cesium at different temperatures were given in Table 3 .

It can be found that all the $\Delta G^{\mathrm{o}}$ values were negative at the temperature range of 288.15 to $328.15 \mathrm{~K}$, conforming that the

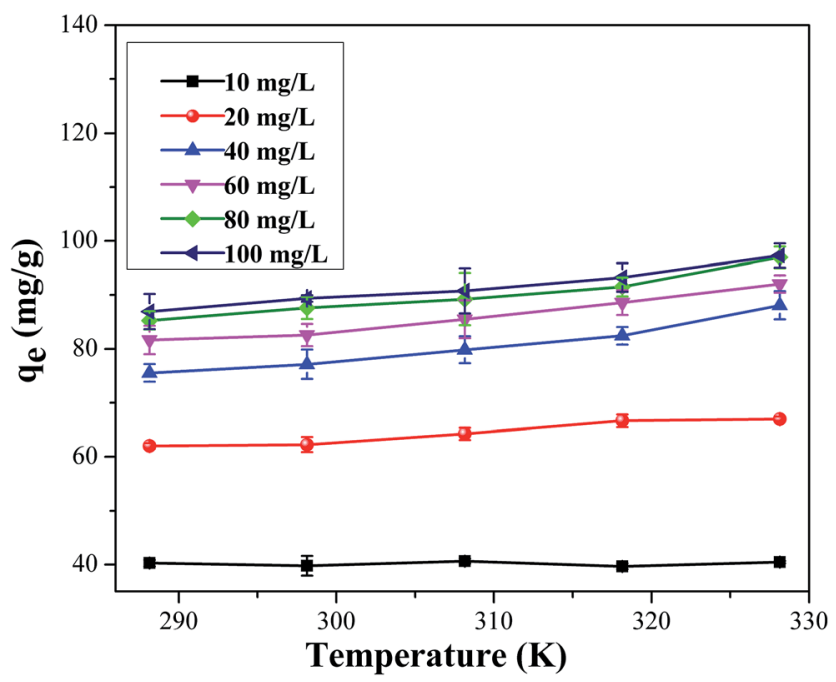

Fig. 10 Effect of temperature on the remove of $50 \mathrm{~mL} \mathrm{Cs}^{+}$for $24 \mathrm{~h}$ at 288.15-328.15 K. adsorption of cesium onto CMC-KCuFC particle was thermodynamically feasible and spontaneous in nature. For the adsorption of cesium the positive values of $\Delta H^{\mathrm{o}}$ indicated that the adsorption was endothermic. Moreover, the positive value of $\Delta S^{\mathrm{o}}$ was interpreted as the result of an increase in the randomness at the solid/liquid interface during the adsorption of cesium on the adsorbent. ${ }^{33}$

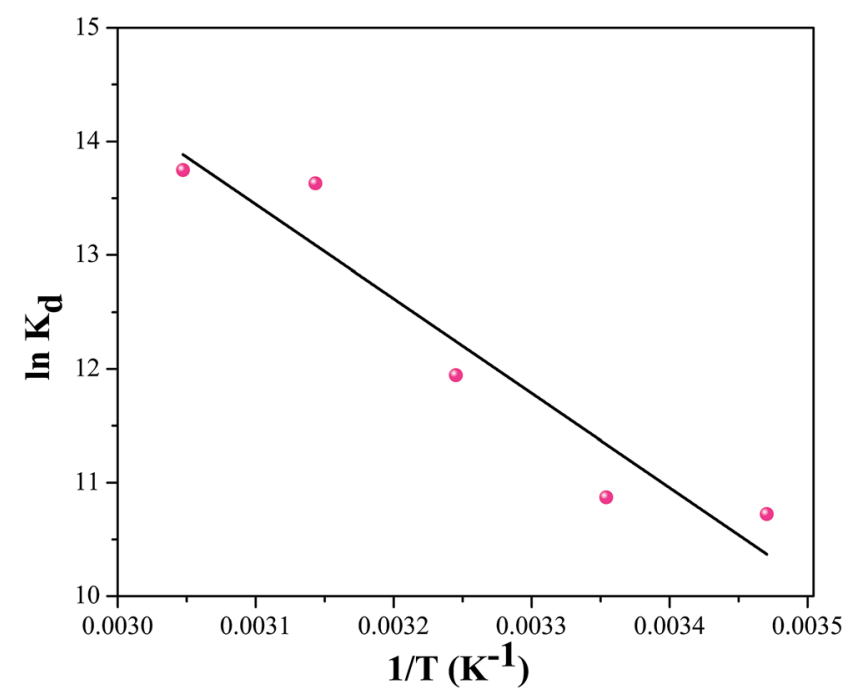

Fig. 11 The relationship between $\ln K_{d}$ and $1 / T$ for $\mathrm{Cs}^{+}$adsorption of CMC-KCuFC particles. 
Table 3 Thermodynamic parameters for the adsorption process of cesium on CMC-KCuFC

\begin{tabular}{lllll}
\hline$T(\mathrm{~K})$ & $\ln K_{\mathrm{d}}$ & $\begin{array}{l}\Delta G^{\mathrm{o}} \\
\left.(\mathrm{kJ} \mathrm{mol})^{-1}\right)\end{array}$ & $\begin{array}{l}\Delta H^{\mathrm{o}} \\
\left(\mathrm{kJ} \mathrm{mol}^{-1}\right)\end{array}$ & $\begin{array}{l}\Delta S^{\mathrm{o}} \\
\left(\mathrm{J}\left(\mathrm{mol}^{-1} \mathrm{~K}^{-1}\right)\right)\end{array}$ \\
\hline 288.15 & 10.723 & -24.843 & 69.087 & 325.974 \\
298.15 & 10.871 & -28.102 & & \\
308.15 & 11.945 & -31.362 & & \\
318.15 & 13.633 & -34.622 & & \\
328.15 & 13.750 & -37.882 & &
\end{tabular}

3.1.6. Effect of competing ions on the adsorption of cesium. The influence of competing cations $\left(\right.$ e.g. $\mathrm{Na}^{+}, \mathrm{K}^{+}, \mathrm{Li}^{+}$, $\mathrm{Ca}^{2+}$ and $\mathrm{Mg}^{2+}$ ) on the $K_{\mathrm{d}}$ value of cesium ion onto the CMCKCuFC particle was investigated. These five cations were selected due to their natural abundance in wastewater. The effect was studied by keeping the concentration of $\mathrm{Cs}^{+}$constant (20 $\mathrm{mg} \mathrm{L}^{-1}$ ), and varying the concentrations of $\mathrm{Na}^{+}, \mathrm{K}^{+}, \mathrm{Li}^{+}, \mathrm{Ca}^{2+}$ and $\mathrm{Mg}^{2+}$ under $\mathrm{pH}(5 \pm 0.02)$ at $298.15 \mathrm{~K}$. In the absence of added cations, the value of $K_{\mathrm{d}}$ was $9493.094 \mathrm{~mL} \mathrm{~g}^{-1}$. The results under competition with added cations were presented in Fig. 12. As the concentration added cations increase from 50 to $250 \mathrm{mg} \mathrm{L}^{-1}$, the $K_{\mathrm{d}}$ value was substantially increased in the following sequence: $\mathrm{K}^{+}<\mathrm{Na}^{+}<\mathrm{Ca}^{2+}<\mathrm{Mg}^{2+}<\mathrm{Li}^{+}$. The $K_{\mathrm{d}}$ value was lowest in the presence of $\mathrm{K}^{+}$, which could be attributed to the closer similarity in hydration radius between $\mathrm{K}^{+}(3.30 \AA)$ and $\mathrm{Cs}^{+}(3.25 \AA)$ than that of the other cations. ${ }^{34}$ Meanwhile, the influences of $\mathrm{Ca}^{2+}$ and $\mathrm{Mg}^{2+}$ cations on the adsorption might be involved in other process or steps except ion exchange, such as nonspecific surface adsorption. ${ }^{35}$

In order to investigate effect of adsorbent dose on the $K_{\mathrm{d}}$ value, the results were shown in Table 4 and Fig. 13. It was obvious that the $K_{\mathrm{d}}$ value of cesium increased rapidly with increasing dose of CMC-KCuFC particles, which might be due to the reason that the adsorbent provided greater surface area and available active adsorption sites with increasing dose of CMC-

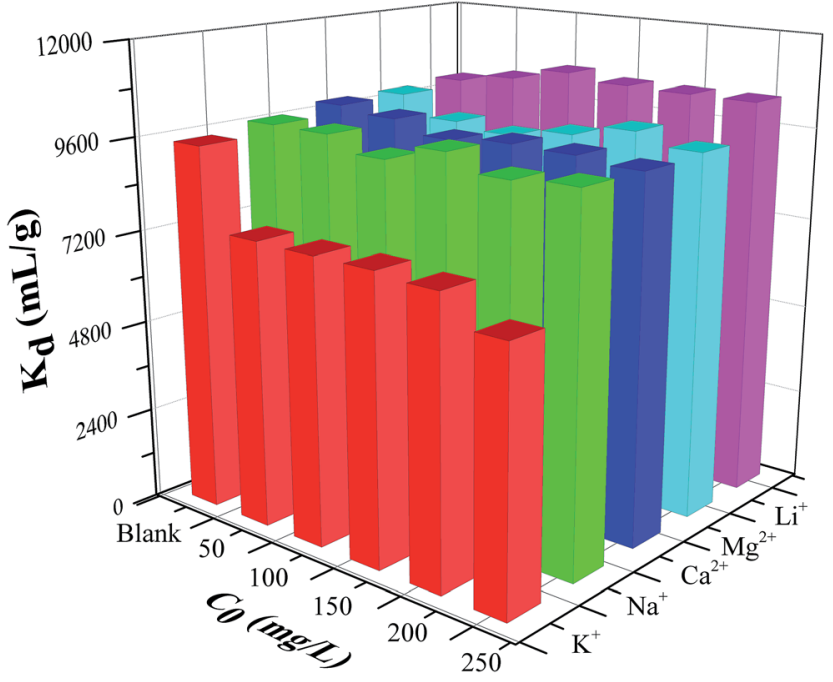

Fig. 12 Effect of competing ions on the remove of $50 \mathrm{~mL} 20 \mathrm{mg} \mathrm{L}^{-1}$ $\mathrm{Cs}^{+}$for $24 \mathrm{~h}$ at $298.15 \mathrm{~K}$.
Table 4 Effect of adsorbent dose on the $K_{d}$ value of cesium ion by the CMC-KCUFC particles [cesium concentration: $20 \mathrm{mg} \mathrm{L}^{-1}$, temperature: $298.15 \mathrm{~K}]$

\begin{tabular}{llll}
\hline $\begin{array}{l}\text { Adsorbent dose } \\
(\mathrm{g})\end{array}$ & $\begin{array}{l}\text { Waste volume } \\
(\mathrm{mL})\end{array}$ & $\begin{array}{l}\text { Adsorption capacity } \\
\left(\mathrm{mg} \mathrm{g}^{-1}\right)\end{array}$ & $\begin{array}{l}K_{\mathrm{d}} \\
\left(\mathrm{mL} \mathrm{g}^{-1}\right)\end{array}$ \\
\hline 0.006 & 50 & 63.177 & 6030.873 \\
0.007 & 50 & 63.280 & 7043.821 \\
0.008 & 50 & 61.994 & 7779.583 \\
0.009 & 50 & 60.727 & 8627.267 \\
0.010 & 50 & 59.372 & 9493.094 \\
0.020 & 50 & 43.927 & $1.099 \times 10^{5}$ \\
0.030 & 50 & 29.862 & $4.117 \times 10^{5}$ \\
0.040 & 50 & 22.438 & $4.533 \times 10^{5}$ \\
\end{tabular}

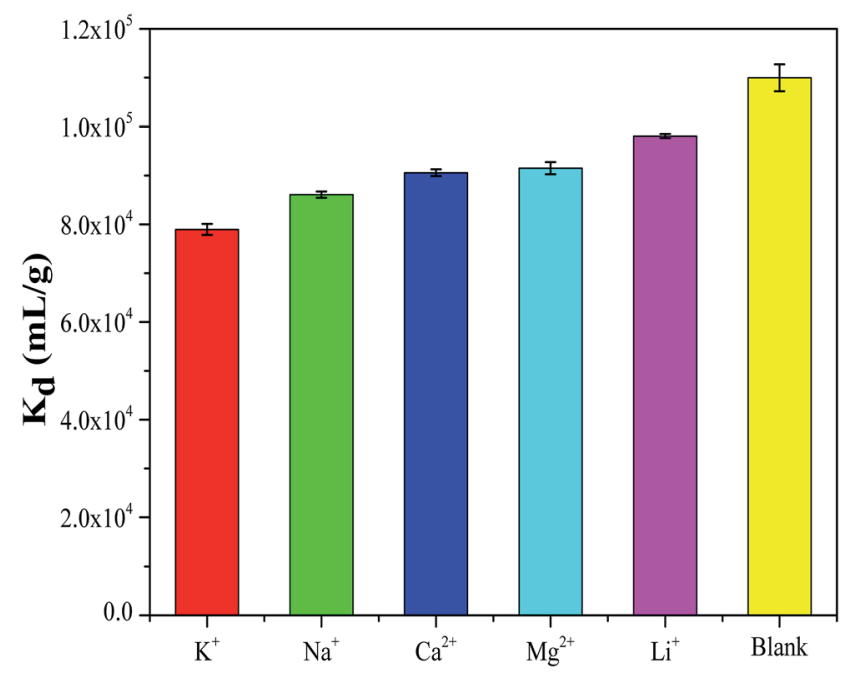

Fig. 13 Effect of competing ions on $K_{d}$ by CMC-KCuFC particles $(\mathrm{pH}$ : 5, initial cesium concentration: $20 \mathrm{mg} \mathrm{L}^{-1}$, adsorbent dose: $0.02 \mathrm{~g}$, temperature: $298.15 \mathrm{~K})$.

KCuFC particles. ${ }^{36}$ Besides, it can be found that the adsorption properties of competing ions for Cs in the high adsorbent dose were consistent with the results obtained in the low adsorbent dose of Cs, and in the condition of high concentration of five cations, the $K_{\mathrm{d}}$ value of cesium ion still remain at a very high level $\left(>8 \times 10^{4} \mathrm{~mL} \mathrm{~g}^{-1}\right)$, the results indicated that the CMCKCuFC particles has good selectivity for cesium ion.

3.1.7. Comparison with other adsorbents. Comparing the adsorption capacity of other cesium adsorbents with that of the CMC-KCuFC adsorbent, ${ }^{9,33,37-39}$ the result was listed in Table 5. It clearly revealed that the adsorption capacity of prepared adsorbent was much higher than most of cesium adsorbents. More important, this adsorbent was prepared only using environmental friendly and inexpensive materials at room temperature. Therefore, CMC-KCuFC adsorbent was a cost-effective adsorbent for cesium removal.

\subsection{Adsorption experiments in a fixed bed column}

3.2.1. Effect of bed height. Effect of bed height (2, 3 and 4 $\mathrm{cm}$ ) on the breakthrough curve at a constant initial cesium 
Table 5 Comparison of maximum adsorption capacity of adsorbents reported in literature for $\mathrm{Cs}^{+}$adsorption $^{a}$

\begin{tabular}{lllll}
\hline Adsorbent & $\mathrm{pH}$ & $T(\mathrm{~K})$ & $q_{\max }\left(\mathrm{mg} \mathrm{g}^{-1}\right)$ & 32.90 \\
\hline Whisker-supported composite & 6 & 298.15 & $3.93 \pm 0.11$ \\
Pre-treated arca shell biomass & 5.5 & - & 16.20 & 38 \\
Prussian-blue-modified magnetite & - & - & $4.94 \pm 0.5$ & 33 \\
Nickel hexacyanoferrate-walnut shell & - & 298.15 & 37.30 & 39 \\
Nanocrystalline mordenite & - & 298.15 & 60.827 & 40 \\
CMC-KCuFC particles & $4-10$ & 298.15 & 7.85 & This study \\
CMC-Cu & $4-10$ & 298.15 & This study
\end{tabular}

${ }^{a}$ Note: '-' represented the information was not given in the references.

concentration $\left(10 \mathrm{mg} \mathrm{L}^{-1}\right)$ and flow rate $\left(2.4 \mathrm{~mL} \mathrm{~min}^{-1}\right)$ was shown in Fig. 14. With an increase of the bed height, the breakthrough curve moves from left to right and both breakthrough point and the saturation point were obviously increased. The explanation was that more available adsorption binding sites at higher bed height, which meant that consequently the total adsorbed cesium ions increased. Moreover, an increase in the bed height resulted in a wide mass transfer zone $^{40}$ which made the breakthrough curves moderately steeper. In fact when the bed height increased, a longer time was required to reach the breakthrough point and saturation point. Therefore, for better performance of a fixed-bed column, a desirable bed height would be important for removal of the metal ions by CMC-KCuFC particles in the practical application.

3.2.2. Effect of influent cesium concentration. Effect of influent cesium concentration $\left(5,10\right.$ and $\left.20 \mathrm{mg} \mathrm{L}^{-1}\right)$ on the breakthrough curve at a constant bed height $(3 \mathrm{~cm})$ and flow rate $\left(2.4 \mathrm{~mL} \mathrm{~min}^{-1}\right)$ was shown in Fig. 15 . An increase in the influent cesium concentration can lead to the faster breakthrough point and saturation point and as a consequence the sharper breakthrough curves shifted to the left. The adsorption

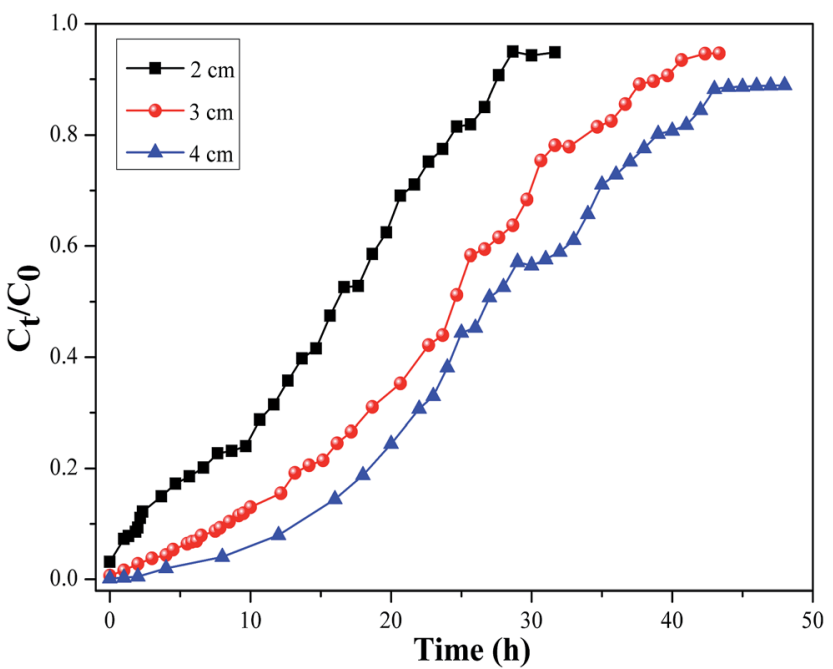

Fig. 14 Effect of bed height on the breakthrough curve of Cs adsorption onto CMC-KCuFC particles $(\mathrm{pH} 5 \pm 0.02$, influent

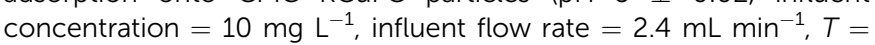
$298.15 \mathrm{~K})$. process reached saturation faster and the breakthrough time appeared earlier with increasing influent concentration. It might be for the reason that the more feeding of adsorbent on per unit surface area of the adsorbent caused the faster saturation of the column bed. ${ }^{41}$ On the other hand, it can be explained that a higher concentration gradient caused a faster transport due to an increase in the diffusion coefficient or mass transfer coefficient. ${ }^{42,43}$

\subsection{Characterization of the materials}

3.3.1. SEM and BET analysis. SEM analysis of CMC-KCuFC adsorbent before and after adsorption were presented in Fig. 16. As shown in Fig. 16a, all the particles were of spherical shape, with a remarkably similar size of $2-3 \mathrm{~mm}$ after drying. It was observed that the outer surface of the dried CMC-KCuFC particles contained large porous channels, and large pores were visible in the SEM image (Fig. 16b). From highly magnified images of Fig. 16c, it was clearly showed that they were highly cross-linked. Lots of KCuFC particles were encapsulated in the network of CMC. Comparing with CMC-KCuFC particles before and after adsorption (Fig. 16c and d), it was obvious that there is no significant shape change. It can be demonstrated that CMC-

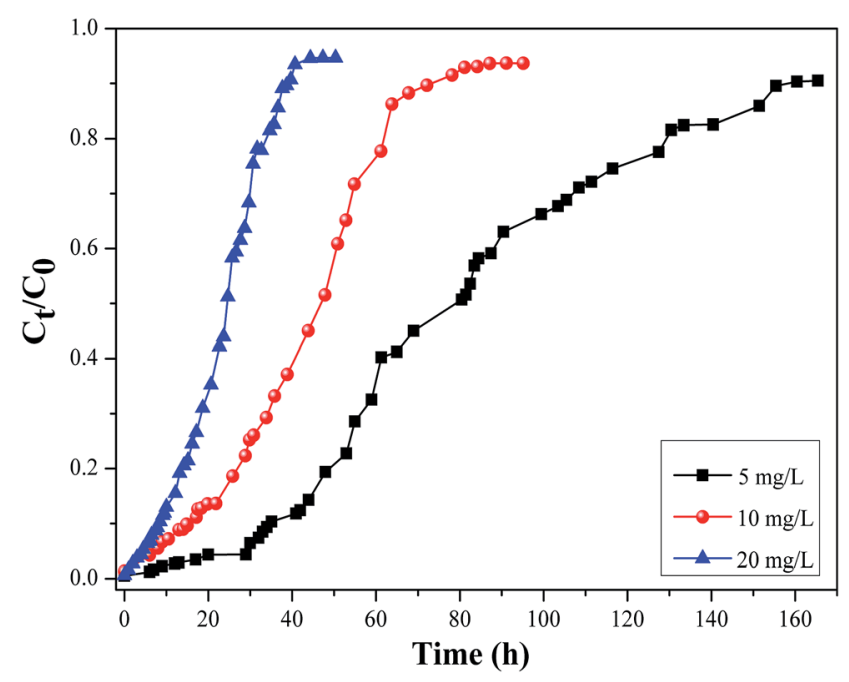

Fig. 15 Effect of influent cesium concentration on the breakthrough curve of Cs adsorption onto CMC-KCuFC particles ( $\mathrm{pH} 5 \pm 0.02$, bed

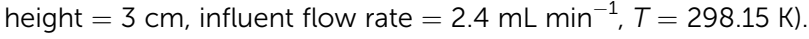



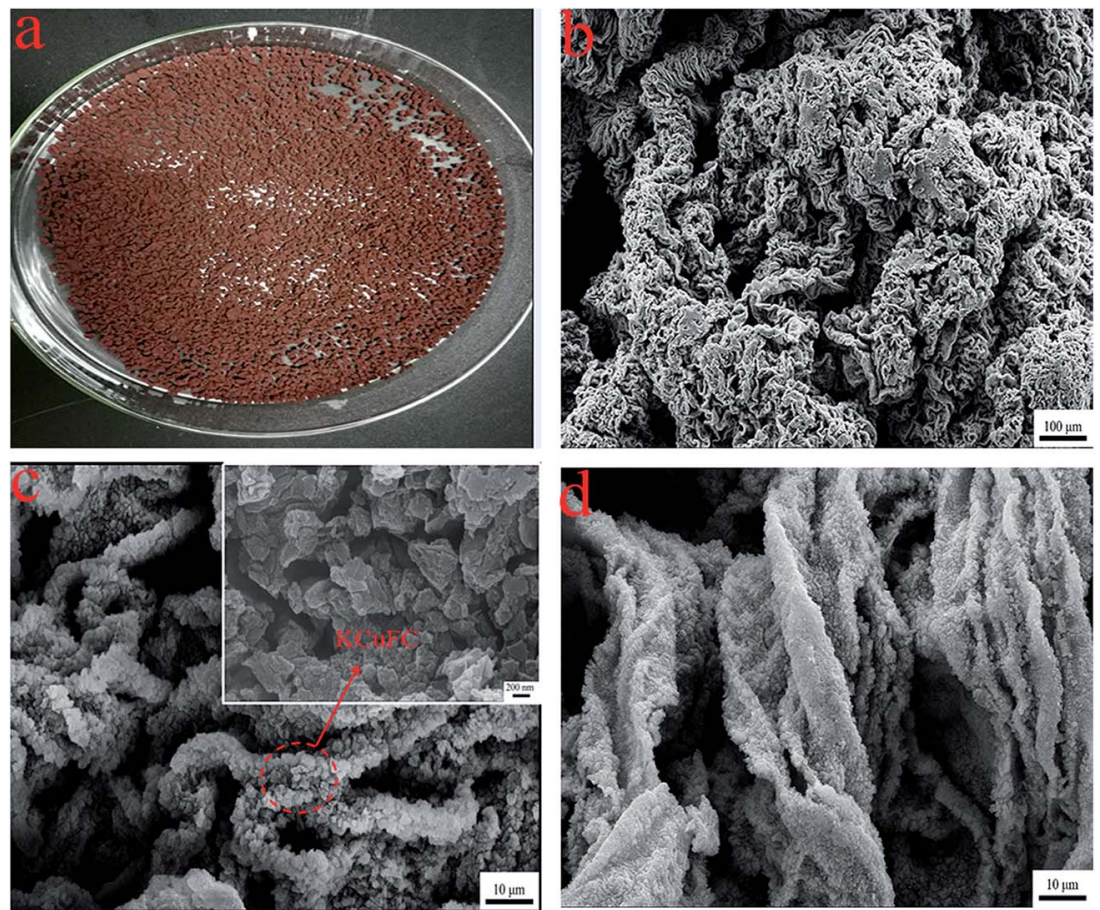

Fig. 16 SEM analyses of the samples: the digital photos of (a) CMC-KCuFC after drying (b) SEM of CMC-KCuFC before adsorption, (c) and inset are SEM of CMC-KCUFC particles after adsorption (higher magnification), (d) is SEM of CMC-KCuFC particles after adsorption.

KCuFC particles had excellent mechanical stability. Meanwhile, the results of multipoint BET analysis were shown in Table 6. It can be seen easily that the BET surface area of CMC-KCuFC particles was $55.275 \mathrm{~m}^{2} \mathrm{~g}^{-1}$, which was more than twice of $\mathrm{CMC}-\mathrm{Cu}$, and the total pore volumes of CMC-KCuFC particles was $0.024 \mathrm{~cm}^{3} \mathrm{~g}^{-1}$, while that of CMC-Cu was $0.0036 \mathrm{~cm}^{3} \mathrm{~g}^{-1}$. Therefore an increase in the total surface and pore volume in the CMC-KCuFC particles would have increased the possibility of internal diffusion.

3.3.2. FT-IR analysis. Shown in Fig. $17 \mathrm{a}-\mathrm{c}$ were the FT-IR spectra of CMC, CMC-KCuFC particles and CMC-KCuFC particles after adsorption, respectively. A broad absorption band at $3429-3432 \mathrm{~cm}^{-1}$ was relative to the $-\mathrm{OH}$ stretching vibration, while the bands around $2919-2923 \mathrm{~cm}^{-1}$ attributed to the $\mathrm{C}-\mathrm{H}$ stretching vibration from $-\mathrm{CH}_{2}$ group. And the absorption band around $1611 \mathrm{~cm}^{-1}, 1422 \mathrm{~cm}^{-1}$ and $1060 \mathrm{~cm}^{-1}$ were referred to the stretching vibration of COO- (asymmetric), COO- (symmetric) and $\mathrm{C}-\mathrm{O}$ group, respectively. ${ }^{43}$ Comparing the spectrum of the CMC-KCuFC with that of the CMC, a sharp absorption band located at $2096 \mathrm{~cm}^{-1}$ appeared which was attributed to the $\mathrm{C} \equiv \mathrm{N}$ stretching vibration. ${ }^{1}$ Compared Fig. $17 \mathrm{a}$

Table 6 Pore structure parameters of CMC-Cu and CMC-KCuFC particles

\begin{tabular}{lll}
\hline Sample & $\begin{array}{l}\text { Surface area } \\
\left(\mathrm{m}^{2} \mathrm{~g}^{-1}\right)\end{array}$ & $\begin{array}{l}\text { Total pore volume } \\
\left(\mathrm{cm}^{3} \mathrm{~g}^{-1}\right)\end{array}$ \\
\hline $\mathrm{CMC}-\mathrm{Cu}$ & 37.181 & 0.0086 \\
$\mathrm{CMC}-\mathrm{KCuFC}$ & 55.275 & 0.0240
\end{tabular}

with $17 \mathrm{~b}$, two smaller peaks at 494.8 and $600.5 \mathrm{~cm}^{-1}$ were assigned to $\mathrm{Fe}^{2+}-\mathrm{C} \equiv \mathrm{N}-$ and $-\mathrm{C} \equiv \mathrm{N}-\mathrm{Cu}^{2+}$ in-plane deformation vibration. ${ }^{16,19}$ All these characteristic peaks clearly suggested that the expected KCuFC particles in the CMC-KCuFC particles were successfully prepared.

3.3.3. EDX analysis. EDX analysis spectra of adsorbents were shown in Fig. 18. Comparing Fig. 18a and b, the element peaks of $\mathrm{N}, \mathrm{Fe}, \mathrm{C}, \mathrm{Cu}$ and $\mathrm{K}$ were recorded in the EDX spectra of CMC-KCuFC particles (Fig. 18b). After the $\mathrm{Cs}^{+}$adsorption, new peaks corresponding to cesium ion appeared (Fig. 18c), which

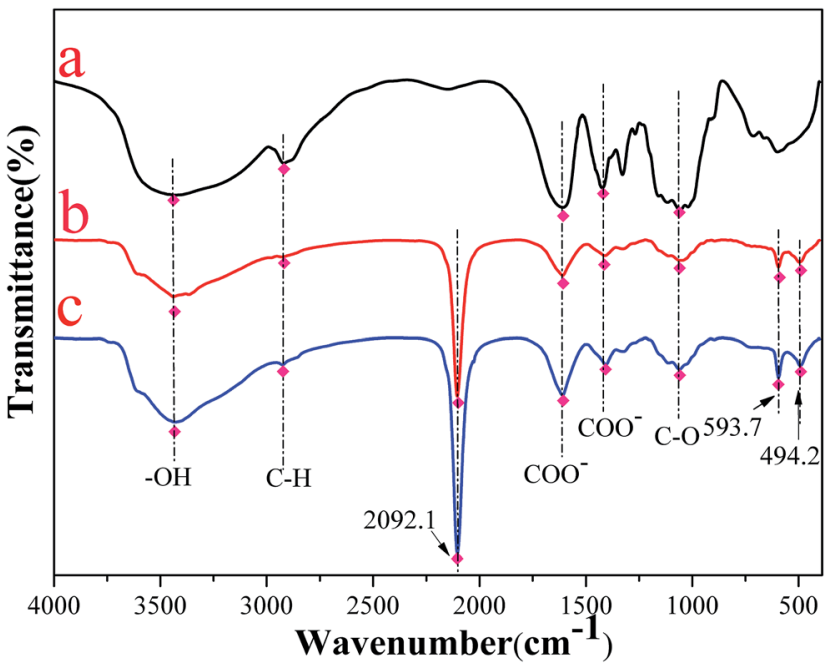

Fig. 17 FT-IR spectra of the samples: (a) CMC, (b) CMC-KCuFC particles, (c) CMC-KCuFC particles after adsorption. 


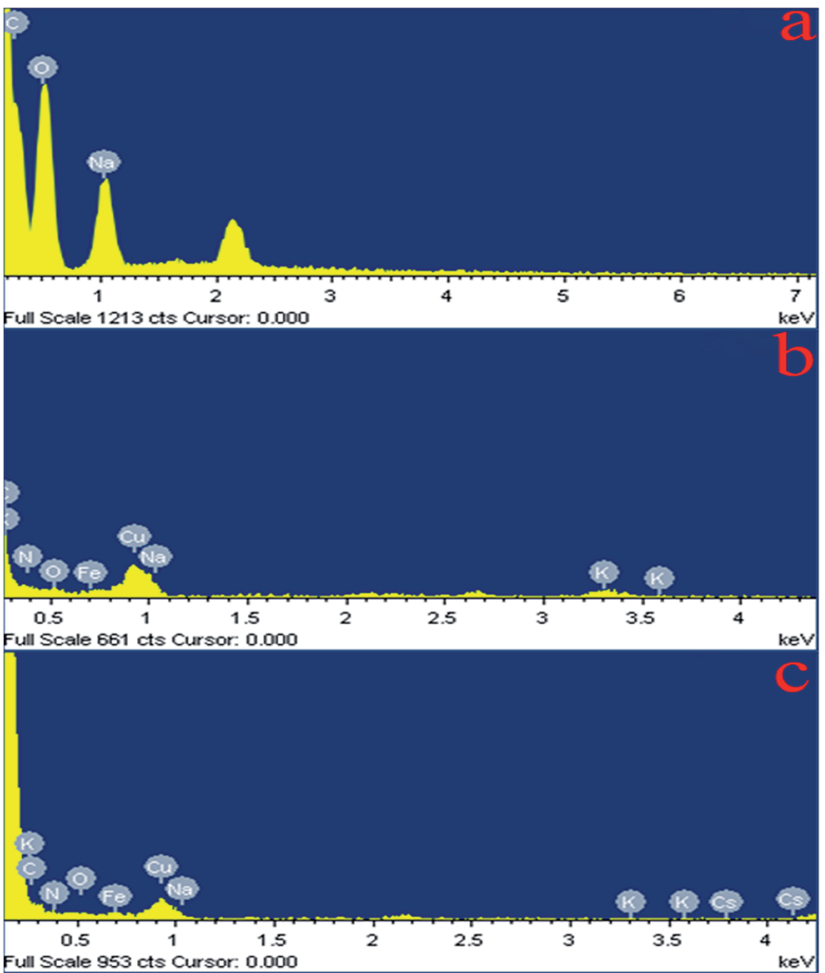

Fig. 18 EDX micrographs of (a) CMC, (b) CMC-KCuFC, (c) CMCKCuFC-Cs.

elucidated that $\mathrm{Cs}^{+}$was effectively adsorbed onto CMC-KCuFC adsorbent.

The percentage of surface atomic concentration determined by EDX spectra is listed in Table 7. Element content of $\mathrm{Na}$ and $\mathrm{Cu}$ before and after reaction are changed from $7.53 \%$ and 0 to $0.26 \%$ and $6.09 \%$, respectively. Which shows that $\mathrm{Na}^{+}$along with $\mathrm{Cu}^{2+}$ participated in the ion exchange. Moreover, element content of $\mathrm{K}$ change from $2.30 \%$ to $0.06 \%$ before and after Cs adsorption, indicating that the $\mathrm{K}^{+}$is exchanged with $\mathrm{Cs}^{+}$.

3.3.4. XRD analysis. XRD analysis of $\mathrm{CMC}, \mathrm{CMC}-\mathrm{Cu}$ and CMC-KCuFC were given in Fig. 19. The characteristic peaks for $\mathrm{CMC}-\mathrm{Cu}$ were not observed, which was considered to be the amorphous structure of $\mathrm{CMC}-\mathrm{Cu}$. Similar result was obtained for the XRD profile for FPPB nanocomposite. ${ }^{44}$ After the growth of KCuFC, a few new diffraction peaks appeared at $44.8^{\circ}, 40.0^{\circ}$, $35.7^{\circ}, 24.9^{\circ}$ and $17.6^{\circ}$ were assigned to the (l $\left.\begin{array}{lll}4 & 2 & 2\end{array}\right),\left(\begin{array}{lll}4 & 2 & 0\end{array}\right),\left(\begin{array}{lll}4 & 0 & 0\end{array}\right)$, ( $\left.\begin{array}{lll}2 & 2 & 0\end{array}\right)$ and ( $\left.\begin{array}{lll}2 & 0 & 0\end{array}\right)$ plane, which agreed with KCuFC crystal (JCPDS card no. 53-0084). Taken together with the IR analysis, it can be inferred that presence of KCuFC was dispersed in the polymer matrix.

3.3.5. TGA analysis. Thermogravimetric analysis (TGA) curves in the oxygen atmosphere of $\mathrm{CMC}, \mathrm{CMC}-\mathrm{Cu}$ and $\mathrm{CMC}-$ KCuFC were shown in Fig. 20. These composites showed the initial weight loss at $33-170{ }^{\circ} \mathrm{C}$, was related to the evaporation water molecules. The major mass loss of $\mathrm{CMC}$ begun at $260{ }^{\circ} \mathrm{C}$ (11\%), whereas the major mass loss of the composite $\mathrm{CMC}-\mathrm{Cu}$ started at $160{ }^{\circ} \mathrm{C}(14 \%)$, and the composite CMC-KCuFC exhibited its major weight loss at $165{ }^{\circ} \mathrm{C}(22 \%)$. Between $339^{\circ} \mathrm{C}$ and $441{ }^{\circ} \mathrm{C}$, CMC-KCuFC particles showed a more obvious
Table 7 Atomic concentrations on the absorbent surfaces obtained using EDX (data precision is $\pm 5 \%$ )

\begin{tabular}{llllll}
\hline & \multicolumn{7}{l}{ Atomic concentration (\%) } \\
\cline { 2 - 6 } Sample & $\mathrm{Na}$ & $\mathrm{Cu}$ & $\mathrm{Fe}$ & $\mathrm{K}$ & $\mathrm{Cs}$ \\
\hline CMC & 7.53 & 0 & 0 & 0 & 0 \\
CMC-KCuFC & 0.26 & 6.09 & 7.36 & 2.30 & 0 \\
CMC-KCuFC-Cs & 0.23 & 5.65 & 6.47 & 0.06 & 1.36
\end{tabular}

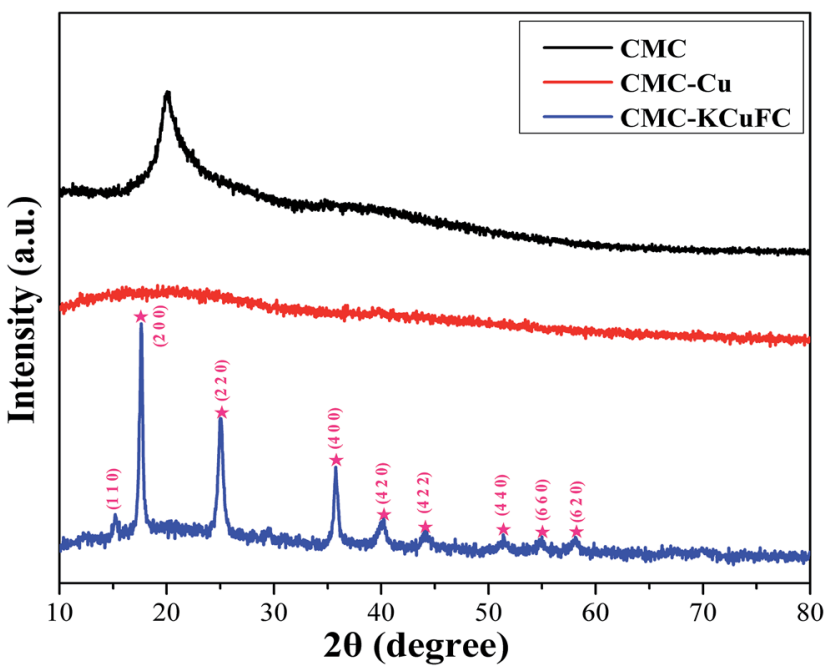

Fig. 19 XRD spectra of the samples: CMC, CMC-Cu and CMCKCuFC particles.

weight loss compared with $\mathrm{CMC}$ and $\mathrm{CMC}-\mathrm{Cu}$, corresponding to the decomposition of the cyanide group. ${ }^{45}$ The rapid weight loss in the range of $220-370{ }^{\circ} \mathrm{C}$ both in the CMC and CMC$\mathrm{KCuFC}$ was attributed to polymer degradation. After heating up to $750{ }^{\circ} \mathrm{C}$, about $27 \%$ residue was left as charred mass. As it can

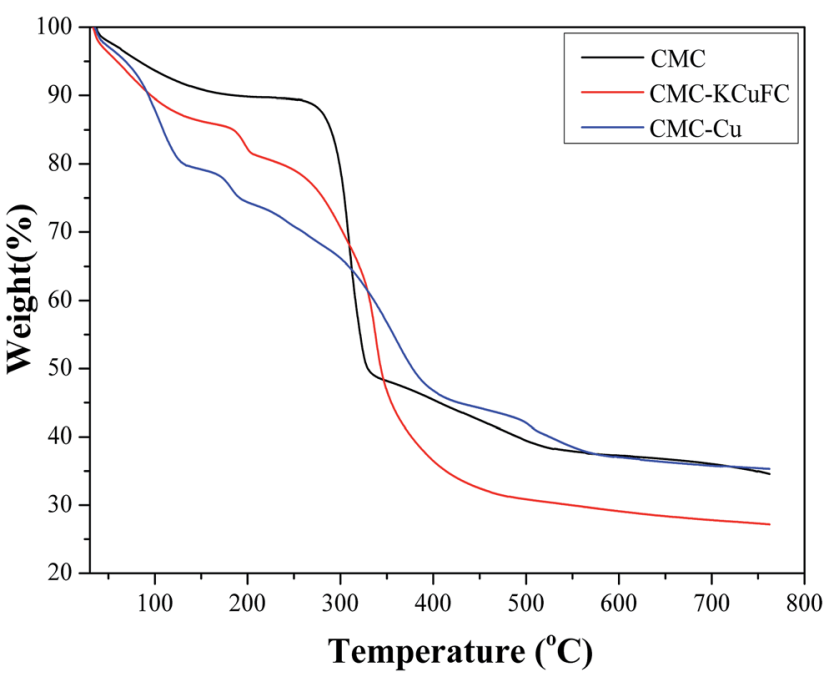

Fig. 20 TGA curves of the samples: CMC, CMC-Cu and CMC-KCuFC particles. 
be observed from these results, the prepared composite was stable up to $180{ }^{\circ} \mathrm{C}$.

3.3.6. Mechanism of Cs adsorption. To understand the $\mathrm{Cs}^{+}$ adsorption mechanism of CMC-KCuFC particles, based on the adsorption models with the analysis of SEM, FT-IR, EDX discussed in the above sections, the mechanism of CMC-KCuFC particles formation and cesium adsorption by $\mathrm{CMC}-\mathrm{KCuFC}$ particles can be proposed in Fig. 21. It could be conclude that ion-exchange reactions between $\mathrm{Na}^{+}$and $\mathrm{Cu}^{2+}$. The process was shown in Fig. 21A.

KCuFC was a cubic, lattice-based, crystal with $\mathrm{Cu}^{2+}$ and $\mathrm{Fe}^{2+}$ atoms occupying alternate corners of the cubic lattice, and cyanide groups on the edges, the $\mathrm{Cu}^{2+}$ ions were octahedrally coordinated to the nitrogen from the cyanide bridge, and the $\mathrm{Fe}^{2+}$ linked to their carbon ends. $\mathrm{Fe}^{2+}$ was six fold carboncoordinated, while $\mathrm{Cu}^{2+}$ was six fold nitrogen coordinated. In the adsorption process of $\mathrm{Cs}^{+}$uptake by CMC-KCuFC, adsorption kinetic study showed that Cs adsorption on the CMCKCuFC was controlled by chemisorption. That was to say, the adsorption process was dependent on the number of available adsorption sites on the adsorbent surface, and was eventually controlled by the binding of $\mathrm{Cs}^{+}$to the surface or internal of the adsorbent. In addition, we investigated the changed values of the concentrations of $\mathrm{Cs}^{+}$and $\mathrm{K}^{+}$before and after adsorption, the results were shown in Table 8 . It was observed that the amount of $\mathrm{K}^{+}$in the solution increased from 0 to $0.031 \mathrm{mmol}$ while the amount of $\mathrm{Cs}^{+}$decreased from 0.038 to $0.025 \mathrm{mmol}$. Thus, as predicted, the exchange mechanism being the insertion of Cs ions into KCuFC crystal lattice, and concurrently displaced $\mathrm{K}$ ions from the lattice. The process was shown in
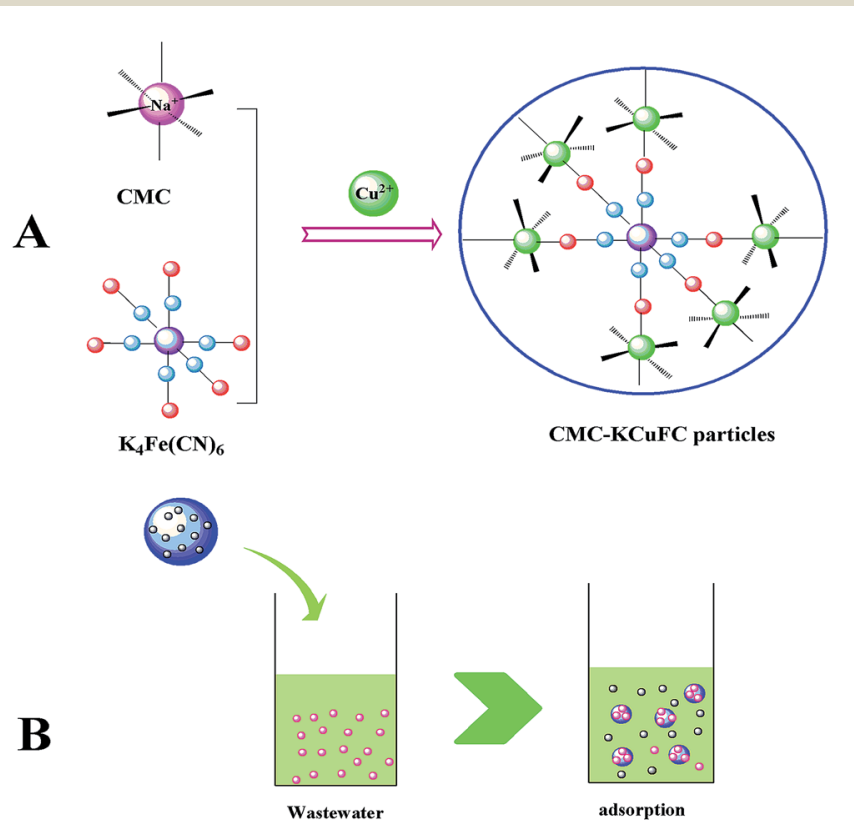

CMC-KCuFC particles $\bigcirc \mathrm{Cs}^{+} \bigcirc \mathrm{K}^{+}$

Fig. 21 (A) Schematic diagram of the fabrication process of CMCKCUFC particles, (B) supposed mechanism of the adsorption of cesium.
Table 8 The changed values before and after adsorption [initial concentration of $\mathrm{Cs}^{+}: 100 \mathrm{mg} \mathrm{L}^{-1}$, dose: $\left.0.05 \mathrm{~g}, \mathrm{~T}: 298.15 \mathrm{~K}\right]$

\begin{tabular}{lll}
\hline Material & $\mathrm{Cs}^{+}(\mathrm{mmol})$ & $\mathrm{K}^{+}(\mathrm{mmol})$ \\
\hline CMC-KCuFC before adsorption & 0.038 & 0 \\
CMC-KCuFC after adsorption & 0.025 & 0.012 \\
\hline
\end{tabular}

Fig. 21B, and this is similar to the mechanism of cesium removal using $\mathrm{K}_{2} \mathrm{CuFe}(\mathrm{CN})_{6}$ adsorbent as ref. 46 .

\section{Conclusions}

The CMC-KCuFC adsorbent was successfully synthesized via an syringe pump device and used for removal of cesium from water. Batch experiments were investigated for the adsorption property of CMC-KCuFC adsorbent, and the results showed a high adsorption capacity was $60.827 \mathrm{mg} \mathrm{g}^{-1}$ for $\mathrm{Cs}^{+}$. The adsorption behavior of CMC-KCuFC fitted well with Freundlich isotherm models and the pseudo-second-order kinetic model. In addition, studies with the effect of $\mathrm{pH}$ confirmed that these particles can be used effectively over the $\mathrm{pH}$ range of 5-10. Moreover, the CMC-KCuFC with adsorbed $\mathrm{Cs}^{+}$was easily separated from water with filtration. Thus, the simple preparation method and excellent adsorption capacity enabled CMCKCuFC adsorbent to be one of the promising candidates for efficient and sensitive removal of cesium in continuous operation.

\section{Acknowledgements}

This work was supported by the National Decommissioning of Nuclear Facilities and Radioactive Waste Management Research Projects Focus, SASTIND China (2014-806); Science and Technology Project of Qinghai Province (2014-GX-Q04) and key platform fund of Engineering Research Center of Biomass Materials, Ministry of Education (14tdsc01), National Natural Science Foundation of China (21406182). Analytical facilities were mainly provided by the Engineering Research Center of Biomass Materials, Ministry of Education.

\section{References}

1 R. Yi, G. Ye, F. C. Wu, et al., Highly efficient removal of ${ }^{137} \mathrm{Cs}$ in seawater by potassium titanium ferrocyanide functionalized magnetic microspheres with multilayer core-shell structure, RSC Adv., 2014, 4, 37600-37608.

$2 \mathrm{E}$. Calabrese, Improving the scientific foundations for estimating health risks from the Fukushima incident, Proc. Natl. Acad. Sci. U. S. A., 2011, 108, 19447-19448.

3 C. Dwivedi, A. Kumar, J. K. Ajish, et al., Resorcinolformaldehyde coated $\mathrm{XAD}$ resin beads for removal of cesium ions from radioactive waste: synthesis, sorption and kinetic studies, RSC Adv., 2012, 2, 5557-5564.

4 R. R. Sheha, Synthesis and characterization of magnetic hexacyanoferrate (II) polymeric nanocomposite for 
separation of cesium from radioactive waste solutions, $J$. Colloid Interface Sci., 2012, 388, 21-30.

5 T. Sangvanich, V. Sukwarotwat, R. J. Wiacek, et al., Selective capture of cesium and thallium from natural waters and simulated wastes with copper ferrocyanide functionalized mesoporous silica, J. Hazard. Mater., 2010, 182, 225-231.

6 A. Y. Zhang, W. W. Zhang, Y. N. Wang, et al., Effective separation of cesium with a new silica-calix [4] biscrown material by extraction chromatography, Sep. Purif. Technol., 2016, 171, 17-25.

7 E. Makrlik, P. Vanura and P. Selucky, Solvent extraction of cesium into nitrobenzene by using a synergistic mixture of hydrogen dicarbollylcobaltate and polypropylene glycol PPG 425, J. Radioanal. Nucl. Chem., 2011, 287, 981-985.

8 H. Rogers, J. Bowers and D. Gates-Anderson, An isotope dilution-precipitation process for removing radioactive cesium from wastewater, J. Hazard. Mater., 2012, 243, 124129.

9 D. H. Ding, Y. X. Zhao, S. J. Yang, et al., Adsorption of cesium from aqueous solution using agricultural residue-walnut shell: equilibrium, kinetic and thermodynamic modeling studies, Water Res., 2013, 47, 2563-2571.

10 C. Dwivedi, A. Kumar, K. K. Singh, et al., Copper hexacyanoferrate-polymer composite beads for cesium ion removal: synthesis, characterization, sorption, and kinetic studies, J. Appl. Polym. Sci., 2013, 129, 152-160.

11 H. Faghihian, M. Moayed, A. Firooz, et al., Synthesis of a novel magnetic zeolite nanocomposite for removal of $\mathrm{Cs}^{+}$ and $\mathrm{Sr}^{2+}$ from aqueous solution: kinetic, equilibrium, and thermodynamic studies, J. Colloid Interface Sci., 2013, 393, 445-451.

12 A. M. El-Kamash, Evaluation of zeolite A for the sorptive removal of $\mathrm{Cs}^{+}$and $\mathrm{Sr}^{2+}$ ions from aqueous solutions using batch and fixed bed column operations, J. Hazard. Mater., 2008, 151, 432-445.

13 S. P. Mishra, Removal behavior of hydrous manganese oxide and hydrous stannic oxide for Cs (I) ions from aqueous solutions, Sep. Purif. Technol., 2007, 54, 10-17.

14 R. G. Anthony, D. Gu, C. V. Philip, et al., Use of silicotitanates for removing cesium and strontium from defense waste, Ind. Eng. Chem. Res., 1994, 33, 2702-2705.

15 G. Murthy, M. Sivaiah, S. Kumar, et al., Adsorption of cesium on a composite inorganic exchanger zirconium phosphateammonium molybdophosphate, J. Radioanal. Nucl. Chem., 2004, 260, 109-114.

16 A. Nilchi, R. Saberi, M. Moradi, et al., Adsorption of cesium on copper hexacyanoferrate-PAN composite ion exchanger from aqueous solution, Chem. Eng. J., 2011, 172, 572-580.

17 J. Causse, A. Tokarev, J. Ravaux, et al., Facile one-pot synthesis of copper hexacyanoferrate nanoparticle functionalised silica monoliths for the selective entrapment of ${ }^{137}$ Cs, J. Mater. Chem., 2014, 2, 9461-9464.

18 R. Chen, M. Asai, C. Fukushima, et al., Column study on electrochemical separation of cesium ions from wastewater using copper hexacyanoferrate film, J. Radioanal. Nucl. Chem., 2015, 303, 1491-1495.
19 T. Vincent, C. Vincent, Y. Barre, et al., Immobilization of metal hexacyanoferrates in chitin particles for cesium sorption: synthesis and characterization, J. Mater. Chem. A, 2014, 2, 10007-10021.

20 M. A. Olatunji, M. U. Khandaker, H. N. M. E. Mahmud, et al., Influence of adsorption parameters on cesium uptake from aqueous solutions-a brief review, $R S C A d v ., 2015,5$, 7165871683.

21 S. Barkhordari and M. Yadollahi, Carboxymethyl cellulose capsulated layered double hydroxides/drug nanohybrids for cephalexin oral delivery, Appl. Clay Sci., 2016, 121, 77-85.

22 W. W. Zhu, K. Liu, X. Q. Sun, et al., $\mathrm{Mn}^{2+}$-Doped Prussian Blue Nanocubes for Bimodal Imaging and Photothermal Therapy with Enhanced Performance, ACS Appl. Mater. Interfaces, 2015, 7, 11575-11582.

23 S. S. Feng, X. D. Li, F. Ma, et al., Prussian blue functionalized microcapsules for effective removal of cesium in a water environment, RSC Adv., 2016, 6, 34399-34410.

24 A. Shukla, Y. H. Zhang, P. Dubey, et al., The role of sawdust in the removal of unwanted materials from water, J. Hazard. Mater., 2002, 95, 137-152.

25 A. K. Vipin, B. Y. Hu and B. Fugetsu, Prussian blue caged in alginate/calcium particles as adsorbents for removal of cesium ions from contaminated water, J. Hazard. Mater., 2013, 258, 93-101.

26 L. Kong, L. L. Yan, Z. Qu, et al., $\beta$-Cyclodextrin stabilized magnetic $\mathrm{Fe}_{3} \mathrm{~S}_{4}$ nanoparticles for efficient removal of $\mathrm{Pb}(\mathrm{ii})$, J. Mater. Chem. A, 2015, 3, 15755-15763.

27 B. El-Gammal, G. M. Ibrahim and I. M. El-Naggar, Preparation of some resorcinol formaldehyde resins for the separation of ${ }^{134} \mathrm{Cs}$ from acidic waste streams, Desalin. Water Treat., 2014, 52, 4721-4733.

28 Y. S. Ho and G. Mckay, Pseudo-second order model for sorption processes, Process Biochem., 1999, 34, 451-465.

29 C. Dwivedi, S. K. Pathak, M. Kumar, et al., Preparation and characterization of potassium nickel hexacyanoferrateloaded hydrogel particles for the removal of cesium ions, Environ. Sci.: Water Res. Technol., 2015, 1, 153-160.

30 G. Vijayakumar, C. K. Yoo, K. G. P. Elango, et al., Adsorption characteristics of rhodamine $\mathrm{B}$ from aqueous solution onto baryte, Clean: Soil, Air, Water, 2010, 38, 202-209.

31 H. J. Yang, H. Y. Li, J. L. Zhai, et al., Magnetic Prussian blue/ graphene oxide nanocomposites caged in calcium alginate microparticles for elimination of cesium ions from water and soil, Chem. Eng. J., 2014, 246, 10-19.

32 Z. L. Zhang, X. H. Xu and Y. S. Yan, Kinetic and thermodynamic analysis of selective adsorption of Cs (I) by a novel surface whisker-supported ion-imprinted polymer, Desalination, 2010, 263, 97-106.

33 S. Dahiya, R. M. Tripathi and A. G. Hegde, Biosorption of heavy metals and radionuclide from aqueous solutions by pre-treated arca shell biomass, J. Hazard. Mater., 2008, 150, 376-386.

$34 \mathrm{H}$. Long, P. Wu and N. Zhu, Evaluation of $\mathrm{Cs}^{+}$removal from aqueous solution by adsorption on ethylamine-modified montmorillonite, Chem. Eng. J., 2013, 225, 237-244. 
$35 \mathrm{~J} . \mathrm{Wu}, \mathrm{B}$. Li, J. Liao, et al., Behavior and analysis of cesium adsorption on montmorillonite mineral, J. Environ. Radioact., 2009, 100, 914-920.

36 A. Shukla, Y. H. Zhang, P. Dubey, et al., The role of sawdust in the removal of unwanted materials from water, J. Hazard. Mater., 2002, 95, 137-152.

37 Z. L. Zhang, X. H. Xu and Y. S. Yan, Kinetic and thermodynamic analysis of selective adsorption of Cs (I) by a novel surface whisker-supported ion-imprinted polymer, Desalination, 2010, 263, 97-106.

38 T. Sasaki and S. Tanaka, Magnetic separation of cesium ion using Prussian blue modified magnetite, Chem. Lett., 2012, 41, 32-34.

39 K. Y. Lee, M. Park, J. Kim, et al., Equilibrium, kinetic and thermodynamic study of cesium adsorption onto nanocrystalline mordenite from high-salt solution, Chemosphere, 2016, 150, 765-771.

40 E. Oguz and M. Ersoy, Removal of $\mathrm{Cu}^{2+}$ from aqueous solution by adsorption in a fixed bed column and neural network modelling, Chem. Eng. J., 2010, 164, 56-62.

41 J. M. Salman, V. O. Njoku and B. H. Hameed, Batch and fixed-bed adsorption of 2,4-dichlorophenoxyacetic acid onto oil palm frond activated carbon, Chem. Eng. J., 2011, 174, 33-40.

42 I. Kavianinia, P. G. Plieger, N. G. Kandile and D. R. K. Harding, Fixed-bed column studies on a modified chitosan hydrogel for detoxification of aqueous solutions from copper (II), Carbohydr. Polym., 2012, 90, 875-886.

43 K. H. Chu, Fixed bed sorption: setting the record straight on the Bohart-Adams and Thomas models, J. Hazard. Mater., 2010, 177, 1006-1012.

44 H. J. Yang, H. Y. Li, J. L. Zhai, et al., In situ growth of Prussian blue nanocrystal within $\mathrm{Fe}^{3+}$ crosslinking PAA resin for radiocesium highly efficient and rapid separation from water, Chem. Eng. J., 2015, 277, 40-47.

45 J. H. Her, P. W. Stephens, C. M. Kareis, et al., Anomalous non-Prussian Blue structures and magnetic ordering of $\mathrm{K}_{2} \mathrm{Mn}^{\mathrm{II}}\left[\mathrm{Mn}^{\mathrm{II}}(\mathrm{CN})_{6}\right]$ and $\mathrm{Rb}_{2} \mathrm{Mn}^{\mathrm{II}}\left[\mathrm{Mn}^{\mathrm{II}}(\mathrm{CN})_{6}\right]$, Inorg. Chem., 2010, 49, 1524-1534.

46 C. L. Neskovic, S. Ayrault, V. Badillo, et al., Structure of copper-potassium hexacyanoferrate (II) and sorption mechanisms of cesium, J. Solid State Chem., 2004, 177, 1817-1828. 